\title{
La "defensa" aristotélica de la esclavitud de los indios americanos: a propósito del dominium e imperium en la lectura de Juan Ginés de Sepúlveda ${ }^{1}$
}

\section{The so-called Aristotelian "Defense" of Enslaving American Indians: apropos the dominium and imperium according to Juan Ginés de Sepúlveda's Thought}

\author{
Genaro Valencia Constantino \\ https://orcid.org/0000-0002-1226-1182 \\ Universidad Panamericana, México \\ gevalenc@gmail.com
}

\begin{abstract}
Resumen: La defensa de la esclavitud de los indios americanos, que aparentemente Juan Ginés de Sepúlveda sostenía en el siglo xvI, es, como intentaré demostrar a lo largo de este trabajo, un malentendido resultante de interpretaciones poco atinadas y simplistas que no contemplan el tipo de lectura que hizo Sepúlveda de la Política de Aristóteles, la versión latina que publicó, el contexto político y social de la monarquía hispánica durante ese siglo y ciertos conceptos clave del derecho romano. Además, el prejuicio, que Menéndez Pelayo provocó, quizá sin intención, al traducir parte del título del tratado Democrates alter, sive de iustis belli causis apud Indos con "contra los indios", creó un grave estigma desde el siglo XIX que ha condenado a Sepúlveda como defensor de la esclavitud. Con este texto, pretendo evidenciar la lectura e interpretación que él hizo del escrito aristotélico a la luz de algunos condicionantes textuales y contextuales que esclarecen la forma en que el humanista español abordó la cuestión filosófica y política de la conquista indígena.
\end{abstract}

\footnotetext{
${ }^{1}$ Este artículo es una reelaboración del texto que presenté en el International Workshop: Body and Environment (27 y 28 de enero de 2020, Ciudad de México), organizado por la Universidad Nacional Autónoma de México (a través del Centro de Estudios Clásicos del IIFL), la Universidad Panamericana y la Universidad de Princeton, en el marco del proyecto Postclassicisms, de cuya red de investigación soy miembro afiliado. Agradezco a dos personas sin cuyos auspicios estas páginas se habrían quedado en el tintero: a Virginia Aspe Armella, gracias a quien tuve ocasión de acercarme al texto de Sepúlveda en el curso de posgrado que en 2019 impartió para la Maestría en Filosofía Antigua, y a María Elena García Peláez Cruz, quien confió en mí para exponer este texto en dicho taller. Asimismo, quedo agradecido con todos los que, como Bernardo Berruecos Frank, me dieron sus comentarios intra y extra muros para mejorar este documento.
} 
Palabras clave: Aristóteles, Juan Ginés de Sepúlveda, esclavitud, dominium, imperium

AbSTRACT: The so-called Aristotelian defense of enslaving the americans, which Juan Ginés de Sepúlveda supposedly yielded in the 16th century, is, as I shall try to prove along this paper, a misunderstanding produced by careless and simplistic interpretations which do not consider the Sepulveda's approach to Aristotle's Politics, the Latin translation he published, the political and social context on Hispanic Monarchy during that century and some key concepts of Roman Law. Besides, the preconception, created by Menéndez Pelayo, maybe unintentionally, by translating a part of the title of the treatise Democrates alter, sive de iustis belli causis apud Indos, by "against the indians", printed a serious brand on Sepúlveda like a slavery defender since 19th century. With this text, I want to show the reading and interpretation Sepúlveda made about Aristotelian work in the light of textual and contextual conditionings, which make clear the way the spaniard humanist deals with the philosophical and political question of indigenous conquest.

Keywords: Aristotle, Juan Ginés de Sepúlveda, Slavery, dominium, imperium

ReCibIDO: 20/03/2020 • ACEPTADO: 21/05/2020 • VeRsión FinAL: 27/06/2020

\section{INTRODUCCIÓN}

Para os los dar a cognoscer me he sobido aquí, yo que soy voz de Cristo en el desierto desta isla, y por tanto, conviene que, con atención, no cualquiera, sino con todo vuestro corazon y con todos vuestros sentidos, la oigais; la cual voz os será la más nueva que nunca oisteis, la más áspera y dura y más espantable y peligrosa que jamás no pensasteis oir. [...] Esta voz, dijo él, que todos estais en pecado mortal y en el vivís y morís, por la crueldad y tiranía que usais con estas inocentes gentes. Decid, ¿con qué derecho y con qué justicia teneis en tal cruel y horrible servidumbre aquestos indios $?^{2}$

Así empezó, como relata Bartolomé de las Casas, fray Antonio de Montesinos su sermón el 21 de diciembre de 1511 en la isla La Española, en acérrima denuncia por el desalentador escenario de esclavitud de los indios en los albores de la Conquista. De dicha situación se desprende una larga y compleja serie de acaloradas discusiones entre teólogos, juristas y filósofos, de ambos lados del mar Océano, en torno a la naturaleza y condición de los indios americanos respecto de la Corona española. Las disputas por alegatos judiciales y apelaciones al rey de España, que sí tuvieron repercusión en la promulgación de leyes, son las que aportaron con efectividad, aunque no ab-

\footnotetext{
${ }^{2}$ De las Casas 1957, lib. 3, cap. 4.
} 
soluta ni inmediata, algún beneficio favorable para los indios, sin embargo, hubo otras reflexiones que se quedaron en un plano intelectual y filosófico, pero son de gran valor histórico y literario.

Por ello, conviene manifestar, de antemano, que este artículo tiene como único objetivo analizar la visión de Juan Ginés de Sepúlveda en el debate sobre la presunta esclavitud natural de los indios americanos, retomada con base en Aristóteles aparentemente sin una adaptación a las circunstancias del momento, acercamiento común e inadecuado; este análisis se realiza sólo desde un punto de vista textual, sin entrar en la espinosa y discutida cuestión de si existió un verdadero impacto en la realidad social durante el periodo de dominación española, tarea más apropiada para la historiografía y la antropología social que para un trabajo de tintes filológicos y enmarcado, más bien, en la historia de las ideas. ${ }^{3}$ La cita de Montesinos arriba aludida es bastante ejemplar por ser testimonio de una cruenta realidad que, en el caso particular de Ginés de Sepúlveda - quien nunca viajó a las Américas - , no fue comprendida ni abordada (desde un inmaculado pedestal) con la misma perspectiva y actitud con que Bartolomé de las Casas lo hizo tras atestiguar, este último, las crueldades sufridas por los indios a manos de los conquistadores y haber sido, él mismo, encomendero de varios colonos. ${ }^{4}$

Así pues, el análisis propuesto para este estudio consiste en pequeñas secciones que tratan aspectos muy puntuales que van abonando elementos - en especial hay una guía argumental basada en dos conceptos esenciales del derecho romano: dominium e imperium - en vista de una mejor interpretación del pensamiento de Sepúlveda, a propósito de la relectura que hizo de la obra de Aristóteles con el fin de sustentar y fortalecer su posición imperialista. Si no se consideran todos estos elementos en conjunto, el acer-

3 Para sustentar esta aproximación metodológica, en torno a la historia de las ideologías, me apoyo en la semántica histórica, desarrollada por Quentin Skinner, quien propugnaba por un enfoque que atendiera "la matriz social e intelectual" en que surgieron determinadas obras y la generación de un vocabulario "en cuyos términos queda entonces articulado y discutido el concepto" (1985, p. 8), de manera que fuera posible advertir "no sólo los argumentos que [ciertos autores] estaban presentando, sino también las preguntas que estaban enfocando y tratando de resolver, y hasta qué punto estaban aceptando y apoyando, o cuestionando y repudiando, y quizás polémicamente desdeñando, las suposiciones y convenciones prevalecientes del debate político" (p. 11).

${ }^{4}$ La Brevísima relación de la destrucción de las Indias, publicada por Bartolomé de las Casas en 1552 y dedicada a Felipe, para entonces príncipe y heredero de la Corona española, es la exposición de las crueldades perpetradas por los encomenderos en las Indias, de las que el obispo fue testigo: "las conquistas, las cuales no se les podrían conceder [a los soldados españoles] sin violación de la ley natural y divina, y por consiguiente gravísimos pecados mortales, dignos de terribles y eternos suplicios" (De las Casas 1982, p. 73), donde no se cuestiona la legalidad jurídica de la conquista, sino, más bien, se recurre, para condenar el cruel trato, a la ley natural y divina. 
camiento sería incompleto y poco certero. ${ }^{5}$ Igualmente, cabe recordar que el pensamiento sepulvedano, como lo prueban la variedad y numerosa cantidad de libros, estudios y artículos, ${ }^{6}$ abreva de un abanico de fuentes, corrientes y tendencias filosóficas que, para el siglo XVI, estaban a disposición del cordobés, por lo cual, a pesar de la pluralidad de interesantes temáticas, aquí se aborda, únicamente, la apropiación y relectura del argumento aristotélico de la esclavitud filtrado, filológica e ideológicamente, en el Democrates alter y en la traducción latina de Sepúlveda.

Dado que esta traducción latina, publicada en 1548, y el Democrates alter, fechado alrededor de 1545, son anteriores a la Junta de Valladolid (1550-1551), textos en que Sepúlveda fue madurando sus ideas y convicciones, los límites temporales de acción no rebasan la fecha de publicación de la versión latina, pues, si bien el debate en Valladolid representa no sólo un foco importante de información, sino también un punto de inflexión para todas las disquisiciones consecutivas al respecto de dicha controversia, mi objetivo no consiste en contrastar los argumentos de Sepúlveda con aquéllos de Bartolomé de las Casas, sino en rastrear una línea de pensamiento que permita comprender, con mayor precisión, el tratamiento que el humanista español hizo sobre la controvertida esclavitud natural.

El conflicto terminológico procede del concepto natura servus, ${ }^{7}$ que Sepúlveda retomó de la Política de Aristóteles pero que debía responder y adecuarse a las circunstancias específicas de la Conquista. En cualquier caso, las ideas del estagirita quedan parcialmente al margen de la discusión ya que no se trata de un proceso de inalterable transmisión conceptual, sino de una reinterpretación, por parte de Sepúlveda (un Aristóteles "sepulvedizado"),

${ }^{5}$ Un acercamiento filológicamente descuidado conlleva interpretaciones y conclusiones falseadas que imponen estigmas: "He [Sepúlveda] denied vehemently that he advocated either slavery or spoliation for the Indians. Yet he has become for many a scapegoat for Spanish mistreatment of the natives [...] because he opposed the contentious Las Casas, saintly Apostle to the Indians" (Quirk 1954, p. 358).

${ }^{6}$ Para una noticia biográfica y para la relación de la abundante bibliografía de estudios filológicos, históricos y filosóficos sobre la figura y pensamiento de Juan Ginés de Sepúlveda, véase Solana Pujalte 2012.

${ }^{7}$ Quirk 1954,p. 359: "Sepúlveda began the obfuscation of the serf-slave question by being a humanist. Writing in Ciceronian Latin, he found it necessary to use a single term to cover the two entirely different concepts of serf and slave, that is servus". Según esta cita, Quirk parece ver el procedimiento de manera inversa: en lugar de percatarse que, gracias a la connotación que el latín servus ofrece, Sepúlveda partió del concepto latino para describir el fenómeno que tenía delante, Quirk supone, por el contrario, que Sepúlveda, a partir de los dos conceptos en español ("siervo" y "esclavo"), hizo converger en el latín las dos figuras "castellanas". El horizonte cultural e intelectual de Sepúlveda es el latino, claramente de ascendencia griega aristotélica, pero su labor sigue siendo característica del humanismo español que se inscribe en el cultivo de la antigüedad grecolatina. Puede consultarse el profundo estudio de Felipe Castañeda sobre la discusión filosófica de Sepúlveda en torno a la esclavitud natural en Aristóteles 2015b, pp. 135-232. 
con el objetivo de explicar y enfrentar su realidad bajo ciertos supuestos filosóficos: "Too much attention has been focused on what Aristotle meant by natura servus (if we may use Sepúlveda's Latin terminology) instead of examining the idea in a frame of reference which was Spanish and of the sixteenth-century". ${ }^{8}$ Durante dicho periodo (siglos XV y xvI), pese a existir efectivamente en la organización política y social española las figuras de siervo/vasallo y de esclavo - términos entre los cuales las verdaderas funciones se desdibujaban,$-{ }^{9}$ surge esta complicación al interpretar y emplear uno u otro de los vocablos, de donde resulta necesario abordar la problemática desde otro presupuesto léxico y contextual, a partir del lenguaje en latín del que Sepúlveda se apropió y que configuró en su obra, con base en dos conceptos que puedan arrojar algunas luces sobre la naturaleza de dicha discusión: el imperium y el dominium, ${ }^{10}$ conceptos del derecho romano que - como se explicará en seguida - comportan históricamente una "esclavitud" jurídica, reflejo de una sociedad que participaba y se nutría de instituciones políticas y sociales del ius gentium.

\section{ANTECEDENTES HISTÓRICOS Y JURÍDICOS}

Para el momento en que Sepúlveda redacta su diálogo Democrates alter, hacia 1545, había una serie de aspectos históricos y jurídicos en torno a la conquista y sometimiento de los naturales americanos que tenían que ser inexcusablemente conocidos por el humanista cordobés, no sólo porque formaban parte de la realidad monárquica de la época, sino también por su privilegiada posición como confesor del rey Carlos I y preceptor del príncipe Felipe, quienes recibieron de la monarquía precedente una normativa concreta sobre la calidad y naturaleza de los indios, en cuanto súbditos del rey católico.

Desde las postrimerías de la expedición cortesiana, el cruel trato que los españoles mantenían con los indios, primero como conquistadores y,

\footnotetext{
${ }^{8}$ Quirk 1954, p. 358.

${ }^{9}$ Cuestión que también Quirk (1954) se encarga de problematizar.

${ }^{10}$ En su artículo, Tellkamp 2000, pp. 283-289, ya consideraba este concepto de dominium - aunque a partir del estudio de autores de formación teológica más que canónica-jurídica y humanista, como Domingo de Soto, Luis de Molina, entre otros - para explicar una concepción filosófica de la esclavitud durante el siglo xvi, más cercana a la realidad; aún así, conviene destacar que, si bien Sepúlveda contempló también postulados filosóficos en su obra, el primer punto que quiso dejar patente, con tal de prevenir confusiones - lo cual desafortunadamente sí ocurrió-, fue sentar el estatus jurídico, no filosófico, de los indios americanos: "To say that Sepúlveda would enslave or destroy the Indians rather than incorporate them into the Spanish and Christian civilization is to overlook the important linguistic distinction, made by Sepúlveda, bewteen the servus of the philosopher and the servus by law" (Quirk 1954, p. 360).
} 
más adelante, como encomenderos, fue objeto de muy duras críticas de las órdenes religiosas que habían arribado a territorios americanos a evangelizar, de modo que hicieron llegar numerosas quejas a las cortes en España. Además de las denuncias que tenía que enfrentar, el rey Fernando de Aragón, en busca de las vías legales para legitimar su poderío sobre el nuevo continente recién descubierto, convocó en 1512 una reunión en Burgos con el propósito de analizar todo el caso con la participación de reconocidos juristas y teólogos. Dos dictámenes, uno jurídico y otro teológico, propuestos para dicha convención, sirvieron como base para la legislación futura: Juan López de Palacios Rubios, un jurista, redactó el dictamen jurídico con que sustenta la legitimidad de la presencia española en tierras indianas, cuyo texto luego se divulgó bajo el título Libellus de insulis oceanis, y Matías de Paz, un fraile dominico, se encargó del dictamen teológico, cuyo escrito De dominio Regum Hispanice super indos, de matriz escolástica y, especialmente, tomista, tuvo una impronta de gran alcance, más tarde, en la filosofía de la llamada Escuela de Salamanca, encabezada por Francisco de Vitoria. ${ }^{11}$ Gracias a ambos dictámenes se sentaron las bases para las Leyes de Burgos, promulgadas en 1512 tras dicha reunión, estableciendo con ellas tres puntos fundamentales: 1) abolir la esclavitud en el Nuevo Mundo; 2) declarar el dominio español sobre América, y 3) que los indios, hombres libres desde una perspectiva jurídica, no podían ser explotados pero devenían súbditos de la Corona, por lo que debían estar al servicio del rey. ${ }^{12}$ El hecho de que en la realidad los indios siguieran siendo maltratados y tratados como esclavos es un asunto que no compete a este estudio.

Esta distinción y precisión jurídica permite determinar con suficiente claridad cuál era el estatus de los indios: esclavo u hombre libre. La terminología en latín utilizada aquí en toda la cuestión es una buena guía para explicar la naturaleza de este problema. Matías de Paz formuló, para la Junta de Burgos, tres premisas. La primera es esencial: utrum Rex noster Christianissimus possit supra dictos indos regere despotico principatu. A esta interrogante, Matías de Paz respondió que los indios eran libres y no podían ser gobernados despotico principatu, esto es, como si fueran simples esclavos pertenecientes a un señor. El término despoticus hace recordar, de

\footnotetext{
${ }^{11}$ Puede verse Beltrán de Heredia, V., "Un precursor del maestro Vitoria, el Padre Matías de Paz, O.P., y su tratado De dominio Regum Hispanice super Indos", apud De Paz 2017, p. 20.

12 Luego de las Leyes de Burgos de 1512, y hasta la década de los cuarentas - cuando tuvo mayor presencia e impacto la obra de Sepúlveda-, se promulgaron nuevas leyes: "las de Valladolid, las Leyes Nuevas de 1542, las de 1551 [...] Finalmente, fue abolido el régimen de encomiendas, aunque de hecho continuó su existencia en algunos lugares hasta que tuvo lugar su completa extinción" (De Paz 2017, p. 17; cf. Tellkamp 2000, p. 277); si bien hubo nuevas leyes, la condición de los indios como hombres libres no se modificó.
} 


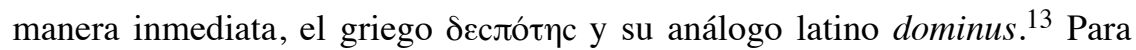
los romanos, el servus formaba parte del patrimonio de una familia, una res mancipi, ${ }^{14}$ de tal modo que podía ser intercambiado, vendido e incluso asesinado (vitce necisque potestas). Cuando Matías de Paz concluye que el monarca no puede gobernar a los indios americanos despotico principatu está delineando su condición, a saber, que éstos, al no ser esclavos, no pueden ser dominados ni tratados como meros objetos de cambio..$^{15} \mathrm{La}$ segunda premisa del dominico reza: an liceat eos tenere sub principatu regali. Este regalis principatus se opone contundentemente al primero en cuanto que el rey no gobernaría como dueño (dominus) de los indios sino en calidad de su rey y príncipe soberano (rex). El resumen y la argumentación de Matías de Paz, a modo de conclusiones y corolarios, son reveladores, y para su tiempo revolucionarios, acerca de la manera de tratar a los indios $\mathrm{y}$, si fuera el caso, de gobernarlos:

Quod ad secundum.

Prima conclusio: non licet principibus christianis bellum contra infideles committere libidine dominandi aut ditandi cupiditate, sed dumtaxat zelo fidei armatis atque fundatis ut per totum orbem terrarum nomen Redemptoris nostri exaltetur atque magnificetur.

Primum corolarium: quapropter non possunt supradicti principes licite terras illorum infidelium invadere quæ numquam fuere subiectæ iugo Salvatoris nostri, si incolæ earum prædicatores fidei catholicæ libenter audire velint eamdemque fidem suscipere parati sunt.

Secundum corolarium: unde convenientissime sequitur quod tales priusquam bellum contra eos iniatur, si congrue possibile est monendi sunt ut Christi fidem verissimam totis viribus amplectantur atque venerentur.

Secunda conclusio: quamvis rex aliquis zelo fidei Salvatoris nostri munitus atque vallatus aucthoritate Papæ licite potuerit contra memoratos indos bellum indicere; iuste tamen poterunt illi se defendere, si supradicta monitio non præcesserit.

${ }^{13}$ En el derecho romano, el concepto de dominium correspondía a la propiedad y posesión civil que tenía un individuo sobre una cosa; se mantuvo como una categoría jurídica importante y primaria de derecho privado, transmitido durante el periodo medieval por el estudio del derecho canónico, influenciando al derecho hispánico e indiano y a todos aquellos sistemas jurídicos deudores de la tradición romana (cf. Wieacker 1957).

${ }^{14}$ Se aplica el concepto de res mancipi a terrenos, esclavos y animales; son bienes que tienen mayor valor y que "requieren formas solemnes para pasar a otro propietario", como mancipatio o in iure cessio (D’Ors 1991, p. 179).

${ }^{15}$ Un pasaje del Digesto ilustra muy bien cómo era concebida la esclavitud romana: servitus est constitutio iuris gentium, qua quis dominio alieno contra naturam subicitur $(D .1,5,4,1$, ed. 1963), donde se explica que la esclavitud es una forma de dominación común entre todos los pueblos. Otro testimonio evidencia la relación y distinción jurídica entre dominus y servus: servi autem in dominium nostrum rediguntur aut iure civili aut gentium: iure civili, si quis se maior viginti annis ad pretium participandum venire passus est. iure gentium servi nostri sunt, qui ab hostibus capiuntur aut qui ex ancillis nostris nascuntur (D. 1, 5, 5, 1, ed. 1963). 
Primum corolarium: unde sic victi non statim efficiuntur sclavi ipso iure, donec pertinaciter nollent supradicto principi obedire, aut se iugo suavissimo Salvatoris nostri subiicere.

Secundum corolarium: quapropter si illi postquam sunt capti cognito nomine Redemptoris nostri, libenter sacrum baptisma suscipere vellint, nullo modo sunt regendi despotico principatu.

Tertia conclusio: auctoritate Summi Pontificis et non aliter, licebit catholico, atque invictissimo regi nostro supradictos indos, regali imperio seu politico, non autem despotico, regere atque sic perpetuo sub suo dominio retinere.

Primum corolarium: unde quicumque eos hactenus servitute despotica premuit, postquam ad fidem sunt conversi ad restitutionem de damno et lucro propter talem servitutem, dumtaxat necessario tenentur. Secus est si ex alia causa.

Secundum corolarium: unde licebit et post suam conversionem ad fidem ab eis exigere aliqua servitia, et forte maiora quam a christianis in partibus istis, dum tamen consona sint fidei nostræ rectoque rationis dictamini, propter expensas et labores illuc pergendo impensos et ut in pace et bono regimine, sub suavissimo Christi iugo, patriam tam distantem a nobis Rex noster catholicus et prudentissimus in perpetuum Altissimo atque Omnipotente Deo favente conservet. ${ }^{16}$

Así pues, Matías de Paz argumenta y explica en qué circunstancias y en qué condiciones un príncipe cristiano podría hacer la guerra y dominar a los indios. A fin de comprender mejor el concepto de regalis principatus y declarar concluyentemente que quienes estuvieran bajo este régimen serían hombres libres, retoma dos categorías del derecho romano que constituían un fundamento importante para las relaciones civiles en la antigua sociedad romana: sui iuris y alieni iuris. ${ }^{17}$ Comenta Matías de Paz: proprie liberi dicuntur [...] qui licet dominis suis obediant tamen sunt sui iuris, et reguntur ad utilitatem et commodum ipsorum potius quam ad utilitatem regentis. Alios enim, si eos regit ad sui commodum et non ipsorum, potius tiranus erga tales quam rex censendus est, ut innuit Philosophus. ${ }^{18}$ Valiéndose de este concepto de sui iuris, explica que quienes fueran gobernados con regalis principatus son dueños de sí mismos jurídicamente, haciendo referencia, simultáneamente, a un pasaje de la obra política aristotélica donde el estagirita define la relación del señor y del supuesto esclavo. ${ }^{19}$

16 De Paz 2017, pp. 94-96. En adelante, las negritas son mías.

${ }^{17}$ La posición que una persona ocupaba dentro de la familia romana definía su condición jurídica: el jefe de la familia (pater familias) era un ciudadano sui iuris, es decir, tenía plena capacidad jurídica en la sociedad y no estaba bajo la potestad de ningún otro individuo, era independiente jurídicamente, mientras que los hijos, aunque, por nacimiento, eran hombres libres, dependían por completo de la voluntad del padre, como alieni iuris, tenidos por "sometidos libres" (D’Ors 1991, pp. 50, 267).

18 De Paz 2017, p. 86: tiranis] tiranus corr. ego.

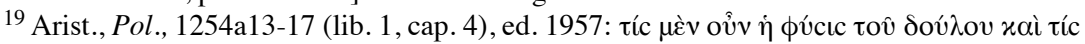

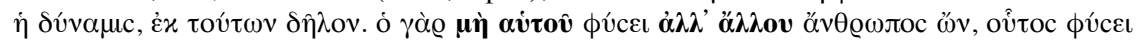


Además de dominium - rescatado luego en el tratado De dominio infidelium et iusto bello de Alonso de la Vera Cruz y adaptado en las obras de Sepúlveda $-{ }^{20}$ el otro concepto clave que debe considerarse en esta cuestión es el imperium.

El imperium, entre los romanos, era un poder de mando absoluto que ciertos magistrados (cónsules y pretores) ejercían para resolver temporalmente cierta especie de conflictos. ${ }^{21}$ El imperium también se ejercía en el ámbito militar: quien detentaba este mando absoluto lideraba las tropas y podía hacer la guerra contra otros pueblos, con previa discusión y aprobación en el Senado. Así, cuando se habla de que los indios debían someterse al imperio del rey, no ha de entenderse de ningún modo dominación o esclavitud -idea correspondiente más bien con el dominium y superada gracias a las Leyes de Burgos - , sino que tendría que pensarse en términos políticos, es decir, que los indios americanos, como eran libres jurídicamente, se proyectaba su condición como vasallos del rey, según la estratificación social del periodo feudal español que quería ser instaurada en Nueva España. Para esta época, el vasallaje constituía una parte esencial de la realidad social y política española, de suerte que el imperium, al que los vasallos se tenían que someter, era, precisamente, al del monarca español, jurando fidelidad a su señor y cumpliendo con ciertas tareas. Por ende, establecida su libertad legal, bajo la visión imperialista y universalista del rey Carlos I, quería aplicarse la misma categoría a los indios del nuevo continente recién encontrado, haciendo de ellos vasallos de la Corona española, gobernados bajo un fuerte poder político de administración y organización, no de dominación. ${ }^{22}$

Resulta claro que Alonso de la Vera Cruz, quien hacia 1554 se encontraba redactando De dominio infidelium et iusto bello, un par de años después de la Junta de Valladolid - momento culminante de toda la polémica indiana aunque no decisivo-, sabía que los indios eran libres por ley, pero gobernados bajo el imperium del rey, por lo cual, las cuestiones planteadas en su escrito abordan otros aspectos igualmente importantes, tendientes a la guerra justa y a la restitución de las tierras a los indios. Debido a que la naturaleza de los indios ya no se ponía en duda, Alonso de la Vera Cruz se pregunta,

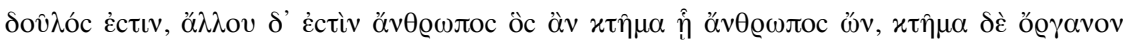

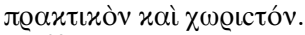

${ }^{20}$ Conviene señalar de paso que el dominium que se trata, según los títulos, en Matías de Paz y Alonso de la Vera Cruz es distinto, pues mientras en el primero se habla del dominio sobre los indios, en el segundo se refiere al dominio que los indios tenían sobre sus tierras, si bien en los dos textos hay temáticas y cuestiones afines.

${ }^{21}$ En el caso de los pretores, quienes eran los más cercanos a la práctica del derecho y ejercían su cargo y función con base en la jurisprudencia, el imperium, la máxima potestad en la república, era un recurso judicial para resolver litigios de carácter civil en el procedimiento formulario romano.

${ }^{22}$ Cf. Quirk 1954 y Traslosheros 1994. 
respecto del imperium que tiene el rey, si la guerra contra ellos puede ser justa y en qué casos lo sería:

581. <Corollarium>. Ex hoc sequitur quod quanquoquidem constat per Alexandrum pontificem commissum Regibus Catholicis et imperatori hoc negotium propagandæ fidei in istis hactenus ignotis provinciis, quod, si imperator misit militem armatum ut prædicatores defenderet ab his infidelibus, quod iuste fuerit factum et absque aliquo scrupulo, tam ex parte imperatoris mittentis, quam ex parte ipsorum militum. Patet: quia iustum est imperium, iusta est etiam executio imperii. ${ }^{23}$

Así pues, sería justo y lícito para el rey hacer la guerra contra los indios en el caso de que atacaran a los predicadores de la fe cristiana, sin embargo, en otro punto concede que non primo pradicatores tales missi, sed a principio venerunt milites armati, qui deterrabant et exspoliabant et occidebant huius Novi Orbis incolas. ${ }^{24}$

En suma, estos antecedentes son fundamentales para comprender el estadio político de los indios respecto de la monarquía al momento de la controversia vallisoletana, con eso la reflexión de Sepúlveda estaría encaminada a las causas justas de la guerra, no a la supuesta esclavitud natural de los indios sobre la cual, aprovechando la ocasión, el cordobés también manifestó e infiltró en sus obras su postura política, como se expondrá a continuación. Que la cuestión principal de la reflexión de Sepúlveda en su Democrates alter eran las causas justas de la guerra no sólo se confirma a partir del título de la obra, sino también en el diálogo, pues se enumeran y se explican las causas con que, a su juicio, podía justificarse hacer la guerra a los naturales americanos. ${ }^{25}$

Como gran estudioso de la doctrina aristotélica y, al mismo tiempo, clérigo español con una fe católica muy firme y crítico de Lutero, Sepúlveda abordó la cuestión de la guerra y su posible compatibilidad con la religión cristiana en su diálogo Gonsalus (1523), con el que se enfrentó a Erasmo; a este tema había también dedicado el Democrates primus (1535); hacia 1529, le hizo llegar una Cohortatio al rey Carlos I invitándolo a abanderar una guerra contra los turcos. En definitiva, resulta más que evidente que los escritos de Sepúlveda están fuertemente marcados con la idea de buscar y justificar las causas para hacer la guerra, no sólo a los indígenas americanos, sino también a otros pueblos que considerase "infieles". Es, pues, de gran

${ }^{23}$ De la Vera Cruz 2007, p. 124.

${ }^{24}$ De la Vera Cruz 2007, p. 142.

${ }^{25}$ Cabe señalar el cuidado que tuvo Sepúlveda al declarar desde el título que las causas serían justas, mas no la guerra, pues él mismo se pronuncia en contra de entablar una guerra irracional: Ad summam, bellum nunquam est nisi cunctanter et gravate, et justissimis ex causis suscipiendum (Sepúlveda 1941, p. 52). 
importancia leer e interpretar las dos obras que ocupan este artículo bajo una guía muy clara: Sepúlveda abordó la cuestión indígena como un reflejo meramente instintivo de sus estudios aristotélicos, en los que trabajó durante años - en vista de un proyecto político imperial al que él mismo se adscribía al ser consejero del rey-, y no al contrario, como resalta y denuncia Vollet, "leyendo a Aristóteles a la luz del problema indígena". ${ }^{26}$

\section{La traducción latina de la Política de Aristóteles}

Según una carta fechada en 1534, dirigida a Giovanni Matteo Giberto, obispo de Verona, Sepúlveda tenía desde antes la intención de publicar una traducción al latín de la obra aristotélica sobre la política, pero fue convencido por dicho obispo para realizar, en primer lugar, una de la ética; dice: librorum Aristotelis 'De republica' commodiorem interpretationem multum sciebam desiderari sperabamque illis meam operam et in eo prastando diligentiam nec inutilem fore nec ingratam, de hoc ipse te celandum non putavi. ${ }^{27}$ Esto demuestra que, si bien sería hasta catorce años después de la epístola mencionada cuando se publicaría su traducción, desde siempre había sido un tema que ocupaba su mente y su reflexión filosófica.

En 1548 se imprime en París la "interpretación" latina que Sepúlveda hace de la Política de Aristóteles. Esta traducción, muy elegante y bien lograda conforme al puro estilo ciceroniano, ${ }^{28}$ supone conocer la especial lectura que Sepúlveda hiciera del escrito aristotélico, aunada a la dificultad de que el texto actual editado probablemente dista en varios aspectos del que pudo tomar como base para su traducción. ${ }^{29}$ Por principio, la edición

${ }^{26}$ Vollet 2002, p. 141.

${ }^{27}$ La carta 1, 9 (Sepúlveda 2003, pp. 29-31).

${ }^{28}$ Es una opinión común entre los estudiosos de Sepúlveda decir que de Cicerón únicamente tomó el estilo latino, pero, a mi juicio, ha de tenerse mayor cuidado con esta afirmación ya que habría que investigar detalladamente, no sólo en la traducción latina sino también en sus otras obras, qué tanto de la filosofía ciceroniana se pudo haber filtrado en su pensamiento. En otra carta $(3,11)$, Sepúlveda escribe: Quod scribis, tibi esse in animo meis monitis parere, qui te peramanter hortatus sum ut in studiis literarum stylique ratione tibi optimum quenque, id est, Ciceronem Ciceronisque aquales ad imitandum proponeres, consilium tuum, cum ex meo manet, non possum non probare (Sepúlveda 2003, p. 98). Se podría conjeturar que, dado que la ratio styli se refiere al estilo de escritura, los studia literarum a que alude son fundamentos doctrinales del pensamiento de Cicerón, lo cual fortalece el argumento de una mayor influencia del orador romano en materia política en el humanista cordobés; siguiendo el ejemplo del arpinate, Sepúlveda tradujo el título aristotélico, exactamente, con el concepto con que Cicerón vertió el platónico res publica, término cargado de una significación política romana.

${ }^{29}$ Para un estudio más preciso, si bien seguí aquí el texto que Ross (1957) publicara para la casa editorial oxoniense, también me di a la tarea de revisar la edición decimonónica de Bekker (1831-1870) y la aldina (1498). 
disponible para inicios del siglo XvI era la de Aldo Manuzio, salida a la luz en varios volúmenes en Venecia entre 1495 y 1498. Como se trataba de la editio princeps de las obras completas de Aristóteles, seguramente por la gran demanda la disponibilidad era mínima fuera de Italia, de modo que, incluso para tiempos de Erasmo, eran libros bastante raros de encontrar. ${ }^{30}$ La otra edición que Sepúlveda podía tener a la mano era la del propio Erasmo, publicada por Johann Bebel en Basilea en $1531 .{ }^{31}$ Durante su estancia en Italia (Bolonia, donde tomó clases con Pietro Pomponazzi, y Roma), viviendo ahí veintiún años (entre 1515 y 1536), tuvo acceso a manuscritos, como narra en algunas cartas, en un intento de comparar variantes y reconstruir un texto más confiable, pero, gracias a los volúmenes que por testamento Sepúlveda legó a la biblioteca de la catedral de Córdoba, se sabe que empleó la edición aldina, ya que en dicha biblioteca aún se resguarda su ejemplar, "jalonado por centenares de notas críticas en que se da noticia de la lectura que presentan cuatro manuscritos y la traducción de Guillermo de Moerbecke", 32 lo cual comprueba su familiaridad con el texto griego y con al menos una traducción latina del tratado aristotélico.

Esta revisión y edición del texto griego, en función de una traducción al latín (interpretatio) ${ }^{33}$ le supuso a Sepúlveda una exégesis particular a fin de determinar, agregando o eliminando pasajes según su criterio, qué partes pudieron pertenecer a un arquetipo textual, lo cual ocasionó que la traducción latina de Sepúlveda en parte difiera, en cuanto al contenido se refiere, de la vulgata y, en casos específicos, se hallen pasajes que no corresponden con el texto griego actualmente conocido. Un ejemplo representativo de esto ocurre en el primer capítulo del libro primero de la traducción latina, que tiene su paralelo con el segundo capítulo del libro primero en la numeración actual (1253a1-5). Se trata de la célebre sentencia aristotélica ötı ó

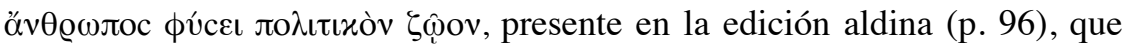
Sepúlveda no introduce, junto con otras líneas adicionales, en este capítulo

\footnotetext{
${ }^{30}$ Van Guilk 2018, p. 342.

${ }^{31}$ A pesar de probablemente tener esta edición a su disposición, Sepúlveda pudo revisarla y no considerarla pues es conocida la crítica que hacía del ejercicio filológico de Erasmo sobre manuscritos de textos griegos, en especial sobre unos comentarios al Nuevo Testamento, incluso desacreditando y cuestionando el conocimiento que tenía Erasmo de la lengua griega, por ejemplo, puede verse la carta 1, 4 (Sepúlveda 2003, pp.9-13).

32 Solana Pujalte y García Pinilla 2017, p. 172.

${ }^{33}$ Como apóstol de Cicerón, Sepúlveda debía saber a la perfección que para el arpinate el ejercicio de traducción (en latín interpretatio) no era un proceso de transferir verbum pro verbo, sino de enunciar con la expresividad del latín el mensaje en griego: "Sepúlveda subraya su preocupación por encontrar las expresiones latinas más adecuadas a las griegas, sobre la base de que cuando en el texto fuente hay un uso oscuro o ambiguo de determinada noción, en latín se debe respetar igualmente ese grado de indeterminación semántica" (Castañeda en Aristóteles 2015b, p. 138), objetividad traductológica que no parece ser absoluta.
} 
primero, sino que las transfiere hasta el segundo, de manera que hizo una reordenación intencional de los contenidos y de los párrafos. ${ }^{34}$

Otro caso de interés, más pertinente para este trabajo, radica en un párrafo cuya traducción está perfectamente ejecutada con el vocabulario latino que Sepúlveda conocía, aún más, probablemente con el que, buscando inducir una lectura particular, quería traducir:

\section{Texto 1.}

Quocirca initio civitates regio imperio gubernabantur, et gentes etiam nunc, propterea quod ex regio imperio parentibus constituebantur. Omnis enim domus $a b$ eo qui maximus natu est, tanquam a rege gubernabatur, ac proinde coloniæ ab cognationem. Et hoc est illud quod Homerus ait: Iure suos quisque, uxores, natosque gubernat.

Sparsim enim, et ad hunc modum antiquitus habitabant, ita cum homines partim etiam nunc, partim antiquitus Regibus parerent, factum est, ut Deos quoque regio imperio gubernari omnes homines dicant, qui Deorum ut formas, sic item vitas suis esse similes arbitrabantur. ${ }^{35}$

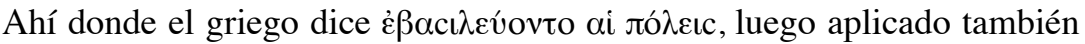
a los hombres, Sepúlveda vierte civitates regio imperio gubernabantur, en cuya expresión la juntura de sustantivo y adjetivo que, por una parte, reproduce la capacidad de gobernar como rey y señor sobre otros y, por otra, añade a partir del término griego el concepto romano de imperare, ${ }^{36}$ sintetiza a la perfección la visión de un gobierno con poderes ilimitados de administración y mando. Al variar luego la versión, ahí donde el griego decía oi

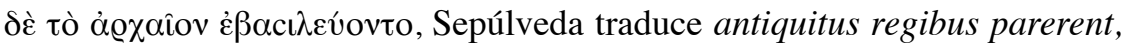
haciendo hincapié en que los hombres obedecían a sus reyes, un aspecto, en consonancia con el regium imperium, presente ya desde Matías de Paz con la idea del regale imperium en los corolarios arriba transcritos.

34 Todavía no he podido revisar hasta qué punto Sepúlveda eliminó, agregó o modificó pasajes que no se encuentran en la edición aldina que era su texto base. Hay que considerar también si toda esta reordenación se debe a lecturas diferentes ofrecidas por los manuscritos que probablemente consultó o bien a una reconfiguración interpretativa del texto por parte del propio Sepúlveda. Véase Solana Pujalte y García Pinilla 2011 y 2017.

35 Sepúlveda 1548, p. 2. Arist., Pol., 1252b19-27 (lib. 1, cap. 2), ed. 1957: dı̀̀ xà̀ tò

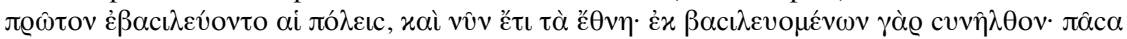

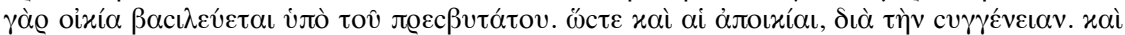

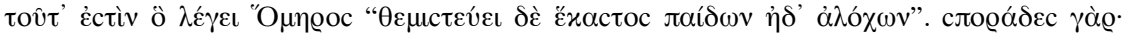

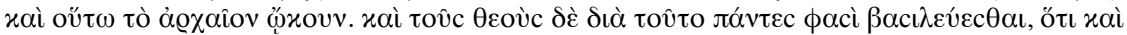

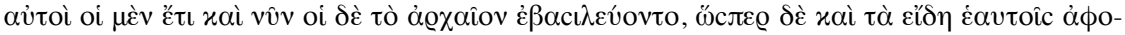

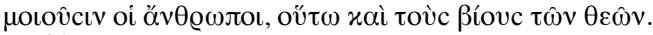

${ }^{36}$ Sirva de ejemplo que los historiadores griegos de época imperial interpretaban imperator con el término griego $\beta \alpha c ı \lambda \varepsilon v ́ c, y$ así con sus demás derivados. 
Estos highlights de la traducción, convenientemente adaptada, son una vaga muestra de que la versión latina de Sepúlveda no es neutral, ${ }^{37}$ sino que está conectada y cargada con su interpretación del texto aristotélico, en términos latinos, y en todo momento a la luz del movimiento imperialista que para entonces encabezaba el rey Carlos I de España, V del Sacrum Imperium. Ha de subrayarse el objetivo de esta traducción, dedicada al príncipe Felipe, donde Sepúlveda lo invita e incita a leerla, en especial por ser obra del filósofo griego, como una importante guía educativa para entender el arte político, no sólo con un enfoque teórico, sino en especial dirigido a la práctica de la gobernación regia, y en el mismo tenor intelectual tan característico de los humanistas de la época:

Tamen hoc præclarum et prudentissimum de Rep. opus. si legere per otium non gravaberis, plurimum, mihi crede, cum ad omnem prudentiam, tum ad regiam facultatem iuvabit. Nam ut cæteras eius multas et magnas commoditates omittam, quæ sit optima Principis educatio, quæ Regis dignitas, quod munus et officium, qui finis propositus, quæ optima ratio civitates et populos administrandi, et se sibique subiectos mortales beatos et felices efficiendi, nusquam ab aliquo philosophorum nec pari gravitate et solertia traditum reperies, nec copiosus aut uberius explicatum. ${ }^{38}$

La Política de Aristóteles es para Sepúlveda un repositorio de información relevante y esencial para reflexionar e instruirse en el arte de gobernar, con especial atención en las relaciones fundamentales de la sociedad ateniense, en concreto en la justificación de la esclavitud que, fundamentándola "en el marco de la economía", para Aristóteles encarna "la necesidad de una mano de obra servil para realizar los trabajos necesarios, en cuya ocupación no puede perder su tiempo el hombre libre dedicado a una función superior", 39 retratada, justamente, en la figura del político o del gobernante. Si bien la supuesta finalidad educativa en exclusivo beneficio del príncipe español no haya sido, en absoluto, el propósito de Sepúlveda y esta epístola pueda tener una intención fuertemente laudatoria, sí muestra la actitud con que se acercó a las ideas que le interesaba extraer del texto aristotélico: justificar causas para una suerte de "esclavitud" política.

${ }^{37}$ Cf. Valverde Abril 2015, sobre las "tergiversaciones" en la traducción latina. Virginia Aspe, especialista del aristotelismo en el periodo novohispano, comenta que esta traducción "no fue tan popular en el ámbito filosófico" probablemente porque "traducía libremente y en ocasiones subordinaba el texto a la elegancia literaria" (Aspe Armella 2018, p. 195), de modo que los lectores, con cierta probabilidad, no hallaron en dicha traducción un texto apropiado para sustentar sus propias interpretaciones filosóficas.

${ }^{38}$ Sepúlveda 1548 , epist. nuncupatoria.

${ }^{39}$ Aristóteles 2015a, pp. 32-33. 


\section{El DEMOCRATES ALTER, SIVE DE IUSTIS BELLI CAUSIS APUD INDOS}

Inmerso en una larga tradición donde Sepúlveda había sido criticado y "tildado de fautor de la esclavitud y apologista mercenario e interesado de los excesos de los conquistadores", en el siglo xIX Menéndez y Pelayo editó y tradujo el Democrates alter, sive de iustis belli causis apud Indos intentando reivindicar el valor histórico de ese diálogo, para entonces manuscrito; ${ }^{40} \sin$ embargo, ya desde la traducción del título, implantó un prejuicio - quizá sin conciencia - , pues tradujo el sintagma apud Indos como "contra los indios", mientras que, discrepando de otros textos de autores contemporáneos que sí incluían la preposición contra, ${ }^{41}$ el título original latino - que Sepúlveda pudo meditar muy cuidadosamente - es claro cuando declara que la guerra se haría en territorio de los pueblos indios, no contra ellos, cosa que, a primera vista, no cambia el sentido, pero no se indica con ello una declaración tan enérgica de guerra y adversidad. La implicación de lo anterior radica en que no sería consecuente entablar la guerra contra los indios que para entonces ya eran considerados, por ley, vasallos del rey español.

La obrita se enmarca en la famosa polémica sobre la legitimidad de la conquista de América por parte de los españoles, querella que derivó en la Junta de Valladolid (1550-1551), la reunión donde se enfrentó Sepúlveda con Bartolomé de las Casas. Redactada alrededor de 1545, momento en que Sepúlveda se encontraba preparando su traducción de la Política de Aristóteles, quedó inédita ya que el Consejo Real de las Indias y el de Castilla prohibieron su impresión a causa de los desfavorables informes que las Universidades de Alcalá y de Salamanca ${ }^{42}$ hicieron con la influencia de Bartolomé de las Casas, quien se pronunció como su principal opositor. No obstante, gracias a sus contactos en Italia, Sepúlveda logró imprimir su Apologia pro libro de justis belli causis (1550) en Roma, a tiempo para acudir a la Junta de Valladolid. Hasta el siglo xix, con Menéndez y Pelayo, sólo se conocía la Apologia, pues el Democrates alter no se imprimió nunca, a pesar de que sí circulaban copias manuscritas en Europa y en Nueva España, como lo comprueba una Real cédula, hasta ahora ignorada y resguardada en el Archivo General de Indias. ${ }^{43}$

\footnotetext{
${ }^{40}$ Sepúlveda 1941, p. viii.

${ }^{41}$ Como el de Alonso de la Vera Cruz: De iusto bello contra indos.

${ }^{42}$ Como consta por Losada $(1984$, p. xv), las negativas de publicación por parte de ambas universidades pueden comprobarse, por un lado, gracias a las actas originales de la Universidad de Salamanca y, por otro, gracias a una Cédula Real "relativa a las gestiones de Sepúlveda en la Universidad de Alcalá", ambos documentos conservados en el Archivo de Simancas.

43 AGI, México, 1089, L. 4, F.300V-301R, manuscrito, "Real cédula a la Audiencia de México para que incaute todos los ejemplares que hubiera en esas tierras de un libro que el doctor [Juan Ginés de] Sepúlveda ha publicado sobre las Indias sin licencia, y los envíe al Consejo de Indias", Unidad Documental Simple, Madrid, 19 de octubre de 1550.
} 
El texto del Democrates alter está compuesto en forma de diálogo y no de disertación o tratado, género que sería adoptado y casi monopolizado por los escolásticos, estructura que después sí ocuparía Sepúlveda para redactar la Apologia, escribe en el prefacio: quastionis summam in morem scholasticum rationibus utriusque partis explicatis redactam. ${ }^{44} \mathrm{El}$ diálogo hace recordar el estilo platónico-ciceroniano, pero es sabido que para el siglo XVI el diálogo era ya un género extensamente cultivado por la mayoría de los humanistas europeos como Erasmo y Vives, entre otros. Los dos personajes que participan en la obra, Demócrates y Leopoldo, mantienen un largo intercambio dialéctico de argumentos y - a más de aludir numerosos ejemplos de autoridad bíblica, del derecho canónico, de padres de la iglesia y algunos más de autores antiguos grecolatinos - esgrimen en su mayoría, para el caso de la supuesta dominación y subyugación de los indios, pruebas entresacadas de la Política de Aristóteles. Si bien es cierto que en el diálogo se mezclan distintas fuentes dignas de tratarse, así como aspectos filosóficos muy particulares, en este texto el foco de interés es exclusivamente la cuestión del dominium e imperium y su correlación con las ideas aristotélicas reinterpretadas por Sepúlveda.

En la Apologia, dicho jurista busca dar una explicación y defender su diálogo Democrates alter de las condenas y críticas que recibió por parte de muchos escolásticos y religiosos, en especial Bartolomé de las Casas, a quienes califica de corrupti homines puesto que pretendían, como asegura, sibi favorem popularem conciliare. Y contundentemente hace una declaración que no deja lugar a dudas:

Ego igitur, ne te mea sententia, de qua quarendum est, lateat, hos barbaros non possesionibus et facultatibus spoliandos esse dico, nec in servitutem redigendos, sed Christianorum imperio subjiciendos, ne fidem aut ejus propagationem impediant, pradicatoribus obsistendo, et Deum per idololatriam blasphemando. ${ }^{45}$

Cabe la posibilidad de que con esta declaración haya intentado calmar los ánimos al certificar que nunca fue parte de su proyecto plantear que los "bárbaros" habían de ser reducidos a esclavos, sino puestos bajo el "imperio" y control de los cristianos, lo cual tampoco resulta inconveniente para concluir que su posición sí era, efectivamente, la que él mismo confirma en el texto: un sometimiento político, no una esclavitud.

Ahora bien, en lo que a los conceptos de dominium e imperium respecta, se pueden apreciar en los siguientes pasajes del Democrates alter algunos paralelismos muy interesantes con la traducción latina:

\footnotetext{
${ }^{44}$ Sepúlveda 1780, p. 329.

${ }^{45}$ Sepúlveda 1780, p. 330.
} 


\section{Texto 2.}

\{Dem.\} ...quoddam esse genus in quo alteri sint natura domini, alteri natura servi... quibus non modo justum esse declarant, sed etiam utile ut serviant natura dominis; quod lege quoque divina sancitum esse videmus. ${ }^{46}$

Este texto está cincelado a partir de su traducción latina:

\section{Texto 3.}

Nam imperare, et parēre, non in necessariis modo, sed etiam in rebus utilibus habentur; et ab ipso statim ortu quædam ita differunt, ut hæc ad parendum, illa sint ad imperandum nata. [...] Non est dubitabile, quin homines quidam ad libertatem nati sint, alii ad servitutem, quibus hoc ipsum ut serviant commodum est atque iustum. ${ }^{47}$

Como se puede observar, en la interpretación latina, ahí donde el grie-

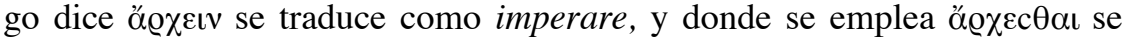
vierte como parēre. Esto resulta conveniente en contraste con el Texto 1, donde por $\beta a c ı \lambda \varepsilon v ́ \varepsilon c \theta \alpha$ se entendía regio imperio gubernari, puesto que, en otro pasaje del mismo capítulo quinto hablando de los señores y los

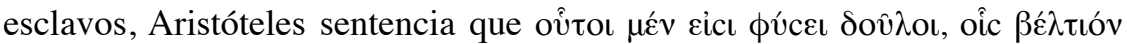

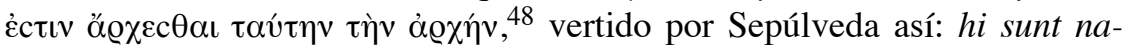
tura servi, quibus optimum est ut hoc imperio gubernentur. ${ }^{49}$ La diferencia

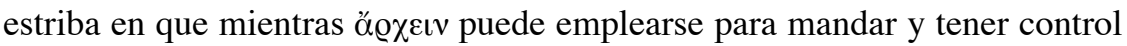
sobre un esclavo, $\beta \alpha \sigma \iota \lambda \varepsilon v ́ \varepsilon ı v$ se utiliza exclusivamente cuando se trata del

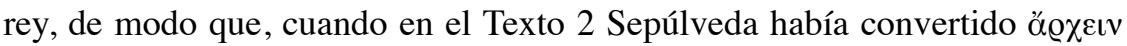

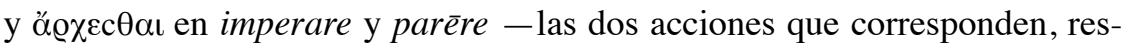

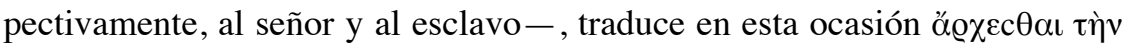

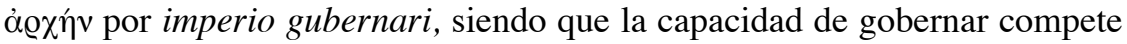
en exclusiva a un rey, no al señor de un esclavo. Puesto que el cordobés era estudioso de la lengua griega y de la latina (de cuño ciceroniano, pues siempre quería escribir en el mejor latín posible), celebrado por ello en Italia y en varias partes de Europa, es consecuente concluir que este supuesto error de traducción es una resignificación consciente, con el fin de argumentar que el señor de un siervo es, más bien, como un rey que con imperium gobierna sobre él, y no como un dueño que lo tiene en dominium, lo que Aristóteles

\footnotetext{
${ }^{46}$ Sepúlveda 1941, p. 84.

47 Sepúlveda 1548, pp. 8-9. Arist., Pol., 1254a21-24; 1255a1-2 (lib. 1, cap. 5), ed. 1957:

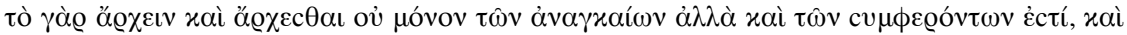

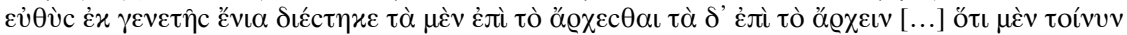

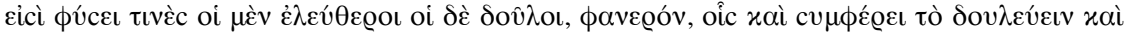

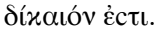

${ }^{48}$ Arist., Pol., 1254b19-20 (lib. 1, cap. 5), ed. 1957.

${ }^{49}$ Sepúlveda 1548, p. 9.
} 
ya había atestiguado como opción viable para algunos, mientras que para

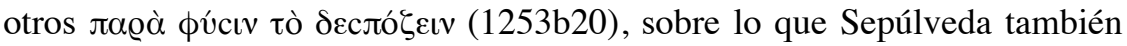
anotó en sus escolios a estos pasajes del libro primero: Alterius esse potest. Qui aquo animo se alterius potestati ac imperio permittit salutis causa, ut illius solertia et ingenio, suo vero labore vivat: qua ratio facit, ut alterius sit. Est enim natus ut sit in alterius potestate..$^{50}$

Aún sobre el imperio, en relación con las causas justas de la guerra, Sepúlveda presenta este parlamento en el Democrates, apelando al derecho natural y divino como una justificación:

\section{Texto 4.}

\{Dem.\} Sunt et aliæ justi belli causæ, quæ minus quidem patent minusque sæpe accident, justissimæ tamen habentur, nitunturque jure naturali et divino; quarum una est, si non potest alia via in ditionem redigantur hi quorum ea conditio naturalis est, ut aliis parere debeant, si eorum imperium recusant; hoc enim bellum justum esse lege naturæ philosophorum maximi testantur. ${ }^{51}$

Este pasaje está recreado por antífrasis de la última parte de la siguiente cita aristotélica, acorde con su traducción, explica que, dado que una guerra puede iniciarse de forma injusta, no por ello una persona, en calidad de cautivo de guerra, puede ser llamada esclavo y estar obligada a obedecer y servir a otros:

\section{Texto 5 .}

Ad summam, nonnulli iure quodam (lex enim ius quoddam est) servitutem ex bello natam iustam esse statuunt, non tamen omnino dicunt: tum quia fieri potest ut bella sint ab iniustis initiis profecta, tum quoniam qui servitute indignus est, hunc esse servum nemo dixerit. ${ }^{52}$

Otro pasaje relevante del Democrates es el siguiente:

\section{Texto 6.}

\{Dem.\} Atque utinam Deus optimus maximus eam mentem regibus omnibus et cujusque reipubl. Principibus tribueret, ut suis quisque rebus contentus esset, nec alienam per avaritiam armatus invaderet, neve gloriam aut famam ex aliorum jactura per sævam et impiam ambitionem quæreret. ${ }^{53}$

${ }^{50}$ Sepúlveda 1548, p. 10. La acotación in alterius potestate recuerda el citado concepto de alieni iuris que contempla, por ejemplo, a los hijos que, aún siendo libres, están bajo la potestad del padre: la patria potestas.

${ }^{51}$ Sepúlveda 1941, p. 80

52 Sepúlveda 1548, p. 11. Arist., Pol., 1255a22-26 (lib. 1, cap. 6), ed. 1957: ö $\lambda \omega c$ $\delta '$

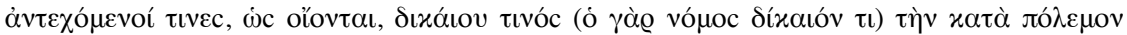

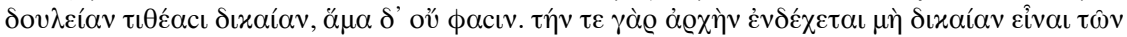

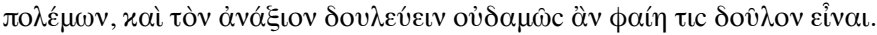

${ }^{53}$ Sepúlveda 1941, p. 50. 
Este fragmento es una recomposición de unas líneas del Pro Roscio Amerino de Cicerón: peto ut pecunia fortunisque nostris contentus sit [...] in alienam pecuniam tam plenam atque praclaram nullo iure invaserit.$^{54}$ Este ejemplo, además de aportar otra prueba de que una de sus fuentes estilísticas, quizás la principal, era Cicerón, es clara demostración, gracias al paralelismo entre el contenido del diálogo y el del discurso ciceroniano, de que Sepúlveda, mediante la lectura de los clásicos, buscaba casos análogos con aquellos que él discutía - por ejemplo sobre la ambición de algunos por apoderarse del patrimonio ajeno a través de la guerra-, lo cual también manifiesta un alto dominio filológico y probablemente también una manipulación consciente de la historia y de la literatura antiguas.

En consonancia con la lectura de autores romanos que hizo Sepúlveda, en particular Cicerón, por quien tradujo el título aristotélico por el concepto romano res publica, el siguiente fragmento del Democrates es muy ilustrativo y presenta varios elementos intertextuales (por un lado, el animus servilis, que ya planteaba Aristóteles en el capítulo quinto del primer libro, y, por otro, el concepto ciceroniano de república, donde los ciudadanos viven al arbitrio y cuidado del rey):

\section{Texto 7.}

\{Dem.\} Quod vero sic habent institutam Rempublicam, ut nihil cuiquam suum sit, non domus, non ager, vel cui velit ex testamento relinquere, cuncta enim sunt in potestate dominorum qui alieno nomine reges appellantur; quod non tam suo quam Regum arbitrio vivant, horum voluntati, ac libidini, non suæ libertati studeant, et cuncta quæ faciant non vi et armis oppressi, sed volentes ac sponte sua, certissima signa sunt barbari, demissi ac servilis animi. ${ }^{55}$

Conviene señalar que Sepúlveda en este pasaje, donde habla de la organización de los indios, retoma la idea de que a los señores, bajo cuya potestad están los esclavos, se les denomina con otro apelativo: reges, recordando el argumento del Texto 3, donde con el "juego" traductológico proyecta que el señor de un esclavo es, más bien, como un rey que con imperium gobierna sobre el siervo, mas no como dueño que tiene dominium. Además, al nombrar como "repúblicas" a los reinos de los aztecas - pues se precisa que el "rey" indígena era Mutezuma -, se amalgama la cuestión del rey/señor con algunas ideas transmitidas ${ }^{56}$ por Cicerón:

\footnotetext{
${ }^{54}$ Cic., Rosc., 6-7, ed. 1905.

55 Sepúlveda 1941, pp. 108-110.

${ }^{56}$ Conviene aclarar que esta comparación de ideas se sustenta en la transmisión del pensamiento político romano, en este caso por vías indirectas o por la lectura de otras obras de Cicerón (concretamente del De officiis) o de otros escritores tardoantiguos que hayan citado al arpinate, ya que, para los tiempos de Sepúlveda, a pesar de que se conocían fragmentos aislados, faltaban tres siglos para que Angelo Mai encontrara, en 1819, el palimpsesto vaticano del De re
} 


\section{Texto 8.}

Deinde aut uni tribuendum est, aut delectis quibusdam, aut suscipiendum est multitudini atque omnibus. quare cum penes unum est omnium summa rerum, regem illum vocamus, et regnum eius rei publicæ statum. cum autem est penes delectos, tum illa civitas optimatium arbitrio regi dicitur. ${ }^{57}$

Gracias a los dos últimos fragmentos, se puede percibir el mecanismo de reconocimiento y asimilación de conceptos: en dicha república los hombres viven al arbitrio de los reyes (en Cicerón de los optimates) y lo hacen volentes ac sponte sua, es decir, voluntariamente y por propia iniciativa, sin que nadie más los constriña por la fuerza o por las armas: non vi et armis oppressi. En el texto del arpinate la pista de esa voluntad de optar por ser gobernados por un determinado grupo de personas es el adjetivo delectos, pues se concedería la libertad, en primera instancia, de elegir si son gobernados y, luego, por quiénes. Y en el Texto 7, Sepúlveda formula que los indígenas subordinados voluntati, ac libidini, non sua libertati studeant, y con el verbo studere pretende moldear la idea de que los indios sean devotos o se entreguen a la voluntad y deseo de los reyes, no en busca de libertad. Ahora, la presunta ventaja de este sometimiento político voluntario radicaría en que los reyes y gobernantes conocen qué es lo mejor y más conveniente para sus súbditos, a lo que, finalmente, se añade un último pasaje con el que termina el Democrates y que sintetiza esta idea (postulada con anterioridad por Aristóteles y referida también por Matías de Paz): ${ }^{58}$

\section{Texto 9.}

$\{$ Dem. $\}$...in populos pacatos justum pro ipsorum natura imperium, mite et humanum, ad summam quale Christianos Principes decet, exerceatur, non modo ad imperantium utilitatem, sed etiam ad subjectorum salutem, ipsorumque naturæ et conditioni aptam libertatem accommodatum. ${ }^{59}$

Debe destacarse que se habla de pueblos que fueron pacati, los pueblos ya sometidos por la guerra: a estos pueblos subyugados, remata Sepúlveda, es necesario imponerles un iustum imperium, el cual será iustum solamente en la medida en que se imponga para la propia seguridad de los súbditos - no obstante podría entenderse salus como salvación, la del alma, en vista de que los príncipes ahí aludidos velan por la fe cristiana - y para una libertad ajustada (apta) conforme con su naturaleza y condición.

publica. Sepúlveda, en sus cartas, cita, efectivamente, el De officiis y Valverde Abril (2003), en su edición de las cartas, hace la correspondencia, si es el caso, con los textos del De re publica ciceroniano.

\footnotetext{
${ }^{57}$ Cic., Rep., 1, 42, ed. 2006.

${ }^{58}$ Cf. supra n. 18.

${ }^{59}$ Sepúlveda 1941, p. 178.
} 
Hasta aquí se ha expuesto una serie de datos y ejemplos, de índole textual y contextual, con los que se intenta hallar una guía más documentada y aproximada al pensamiento de Sepúlveda, para disipar apresurados comentarios tendenciosos de una defensa radicalista de la esclavitud de los indios:

Spanish law and the Spanish language differentiated between the siervo and the esclavo. Whatever the term "slave by nature" meant to Aristotle, the only members of Spanish society who were, or had been, because of their nature, relegated to a lowly position, were the serfs. Thus the ordinary referent to Sepúlveda, and to Las Casas, too, for the Aristotelian natural servitude was evidently this contemporary, or nearly contemporary institution of serfdom, since the slave in Spain was held in bondage, not for what he was, but for what had happened to him. ${ }^{60}$

Así pues, como sostiene Quirk, el referente obvio para Sepúlveda $-\mathrm{y}$ para fray Bartolomé- era la institución española de la servidumbre, acondicionada a partir de las características del vasallaje feudal que desde antiguo había sido implantado en España. Por tanto, si atendiendo a este hecho, para la fecha del Democrates alter (c. 1545), los indios no eran considerados jurídicamente como esclavos - desde las Leyes de Burgos (1512) -, lo cual implicaría una relación de dominium (propiedad) del señor respecto de su esclavo, como expresa el mero concepto romano, ¿qué lectura hizo Sepúlveda del texto aristotélico? Reinterpretó el dominium por imperium. Con este argumento, puede aducirse que la esclavitud a la que están sujetos los indios únicamente es civil y jurídica, por ser éstos casi "ciudadanos" en términos ciceronianos, o más bien súbditos de la Corona española, por lo que se habla de una "esclavitud" jurídica, o dicho con mayor propiedad, de un sometimiento político.

\section{Conclusiones}

A la luz de todos los aspectos expuestos y analizados a lo largo del presente escrito, intentaré concluir, a modo de cierre, con una interpretación basada en dos conceptos hermenéuticos de la estética de la recepción: el de horizonte de expectativas (y experiencias) y el de vacíos. ${ }^{61}$

El primero se refiere a la reconstrucción del horizonte contextual donde tuvieron lugar la creación y composición de una obra en el pasado; el horizonte, para nuestro caso, es binario, pues ocurre en dos momentos históricos distintos y alejados por aproximadamente dos milenios: en la época

\footnotetext{
${ }^{60}$ Quirk 1954, pp. 360-361.

${ }^{61}$ Véase Espino 2017.
} 
de Aristóteles y en la de Sepúlveda, de tal forma que se debe reconstruir el horizonte del autor que produjo el texto antiguo y también el del lector y traductor que, siendo partícipe y consciente de otra realidad, dialoga y moldea su texto desde el antiguo, reconfigurándolo de acuerdo con sus circunstancias particulares, históricas, filosóficas, ideológicas, sociales, políticas, etcétera. Primero, se trata del horizonte que Aristóteles experimentó en vista de la conformación de su Política y, luego, el que experimentó Sepúlveda, leyendo dicha obra aristotélica y considerando su situación política actual ante el problema indiano, para nutrir más adelante los argumentos que verte-

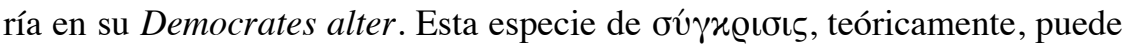
denominarse "fusión de horizontes", cuando el lector reconoce en su propia realidad algunas características del autor antiguo: Sepúlveda reconoce, en Aristóteles, una organización política, semejante a la hispánica, con un gobernante al frente del pueblo. Es en este punto de la lectura que el cordobés interactúa con Aristóteles para 1) enmendar su mensaje, 2) para utilizarlo como plataforma a fin de resaltar sus propias ideas y 3) para rellenar los vacíos que por ciertas razones el antiguo no expresó, sin pensar que faltaron, sino porque su contexto probablemente no podía dar ocasión a tales cuestionamientos.

Tras una lectura continua y un ejercicio filológico muy erudito sobre la obra de Aristóteles, Sepúlveda entendió su contenido y buscó la mejor manera posible, conforme a su horizonte de experiencias caracterizado por una mentalidad moderna del siglo xvI, de reconfigurar y resignificar el pensamiento político aristotélico, actualizando al mismo tiempo el mensaje del estagirita según los tres puntos arriba listados: 1) enmendó el mensaje de Aristóteles para no justificar una esclavitud natural de los indígenas americanos, sino para designarlos vasallos y súbditos, pues por ley eran hombres libres; 2) lo usó como estandarte para hacer brillar sus ideas por medio de una apropiación y manipulación de los conceptos en latín, ya que, para ese entonces, la escolástica todavía estaba vigente y el filósofo griego representaba una figura de autoridad aún importante; 3 ) rellenó algunos "vacíos" que estimaba faltantes, a partir de su interpretación latina del texto aristotélico, consistentes en los conceptos de dominium e imperium, heredados vía derecho romano y cuyas ideas políticas encajaban más apropiadamente con su visión imperialista, y de servus, reinterpretado por completo debido al contexto monárquico y feudal, donde de significar en latín "esclavo" pasa a concebirse como "vasallo" o "siervo", y naturalmente del rey, no de un individuo o señor.

Así pues, Sepúlveda, en su diálogo latino y en su traducción, que aportaron pruebas textuales contundentes, discute cómo los indios americanos podrían ser vistos desde un punto de vista político y jurídico, en contraste con la doctrina de Aristóteles de la que tampoco reniega, y cómo deberían ser 
tratados humanamente por su posición de vasallos respecto del rey quien, sin poseer dominium alguno sobre sus cuerpos, ejercería únicamente un fuerte imperium en calidad de su señor, protector, gobernante y emperador.

Finalmente, gracias al análisis realizado en estas páginas, con evidencias suficientes que lo sustentan, es legítimo afirmar que la postura de Sepúlveda tendía a defender el sometimiento político de los indios americanos, no su esclavitud - aún menos con una justificación de orden naturalista-, de manera que, a partir de este trabajo, resta cuestionarse a qué se debió la condena tan severa de la obra de Sepúlveda: a un malentendido causado por una lectura equivocada y una interpretación inexacta de la terminología, o bien a una censura de tipo político y "académico", quizá por iniciativa de Bartolomé de las Casas, su eterno adversario. En cualquier caso, como aquí se ha demostrado ampliamente, en el discurso de Sepúlveda no hay lugar para la esclavitud natural, sino para la subordinación estrictamente política de los indígenas ante su rey.

\section{BIBLIOGRAFÍA}

\section{Fuentes antiguas}

Aristóteles, Política, trad. Carlos García Gual y Aurelio Pérez Jiménez, Madrid, Alianza Editorial, 2015a.

ARISTóteles, Sobre la república-Libro I, según la traducción latina y escolios de Juan Ginés de Sepúlveda, ed. y trad. Felipe Castañeda y Andrea LozanoVásquez, Bogotá, Universidad de los Andes, 2015b.

Aristotelis Opera, vol. 1, ed. Immanuel Bekker, Berolini, Academia Regia Borussica, apud Georgium Reimerum, 1831.

Aristotelis Politica, ed. William David Ross, Oxford, Oxford University Press (Scriptorum Classicorum Bibliotheca Oxoniensis), 1957.

Aristotle, Opera omnia, vol. 5, ed. Aldus Manutius, Venetiis, 1498.

Corpus Iuris Civilis, ed. Theodor Mommsen y Paulus Krueger, Berolini, apud Weidmanos, 1963.

M. Tulli Ciceronis Orationes, vol. 1, ed. Albert Curtius Clark, Oxford, Oxford University Press (Scriptorum Classicorum Bibliotheca Oxoniensis), 1905.

M. Tulli Ciceronis De re publica, de legibus, Cato maior de senectute, Laelius de amicitia, ed. Jonathan Powell, Oxford, Oxford University Press (Scriptorum Classicorum Bibliotheca Oxoniensis), 2006.

\section{Fuentes modernas}

Aspe Armella, Virginia, Aristóteles y Nueva España, México, Universidad Autónoma de San Luis Potosí, 2018. 
De las Casas, Bartolomé, Historia de las Indias, vol. II, Madrid, Biblioteca de Autores Españoles, 1957.

De las Casas, Bartolomé, Brevísima relación de la destrucción de las Indias, trad. André Saint-Lu, Madrid, Editorial Cátedra (Letras Hispánicas), 1982.

De Paz, Matías, Acerca del dominio de los indios (Libellus circa dominium super indos), ed. y trad. Paulino Castañeda, Jose Carlos Martín de la Hoz y Eduardo Fernández, Salamanca, San Esteban, 2017.

De la Vera Cruz, Alonso, De dominio infidelium et iusto bello. Sobre el dominio de los infieles y la guerra justa, ed. y trad. Roberto Heredia Correa, México, Universidad Nacional Autónoma de México-Instituto de Investigaciones Filológicas (Ediciones Especiales, 44), 2007.

D’Ors, Álvaro, Derecho privado romano, Pamplona, Ediciones Universidad de Navarra, 1991.

Espino Martín, Javier, "Estética de la recepción e Historia de las ideas en el siglo XVIII. La virtus y el honestum ciceronianos en el 'honor nobiliario' de Montesquieu y la 'educación cívica' de Gaspar Melchor de Jovellanos”, Tópicos. Revista de Filosofía, 53, 2017, pp. 325-372.

Quirk, Robert E., "Some Notes on a Controversial Controversy: Juan Ginés de Sepúlveda and Natural Servitude", The Hispanic American Historical Review, 34/3, 1954, pp. 357-364.

Sepulveda Cordubensi, Io. Genesio, Aristotelis de republica libri viII. interprete et enarratore, Parisiis, apud Vascosanum, 1548.

SEPulvedæ Cordubensis, Joannis Genesii Opera, vol. 4, cum edita, tum inedita, accurante Regia Historiæ Academia, Matriti, ex typographia regia De la Gazeta, 1780.

Sepulvedæ Cordubensis, Io. Genesius, Epistolarum libri septem, ed. Juan J. Valverde Abril, Monachi et Lipsiæ, in ædibus K. G. Saur (Bibliotheca Scriptorum Græcorum et Romanorum Teubneriana), 2003.

Sepúlveda, Juan Ginés de, Tratado sobre las justas causas de la guerra contra los indios, trad. Marcelino Menéndez y Pelayo, México, Fondo de Cultura Económica, 1941.

Sepúlveda, Juan Ginés de, Demócrates Segundo o De las justas causas de la guerra contra los indios, ed. y trad. Ángel Losada, Madrid, Consejo Superior de Investigaciones Científicas, $1984^{2}$.

SKINNER, Quentin, Los fundamentos del pensamiento político moderno I: el Renacimiento, México, Fondo de Cultura Económica (Sección de Obras de Política y Derecho), 1985.

Solana Pujalte, Julián, “Juan Ginés de Sepúlveda”, en Juan Francisco Domínguez Domínguez (ed.), Diccionario biográfico y bibliográfico del humanismo español (siglos XV-XVII), Madrid, Ediciones Clásicas, 2012, pp. 773-785.

Solana Pujalte, Julián, e Ignacio Javier García Pinilla, "Erratas y correcciones manuscritas de autor en la traducción latina de la Política de Aristóteles de Juan Ginés de Sepúlveda editada por Michel de Vasconsan (París, 1548)", Cuadernos de Filología Clásica. Estudios Latinos, 31/2, 2011, pp. 293-309.

Solana Pujalte, Julián, e Ignacio J. García Pinilla, “Juan Ginés de Sepúlveda frente a León de Castro: una carta inédita en defensa de su traducción latina de 
la Política de Aristóteles", Cuadernos de Filología Clásica. Estudios griegos e indoeuropeos, 27, 2017, pp. 163-195.

Tellkamp, Jörg Alejandro, "Esclavitud, libertad y derecho: discusiones a partir de la Colonia (1550-1630)", Tópicos. Revista de filosofía, 19, 2000, pp. 275-296.

Traslosheros, Jorge E., "Estratificación social en el reino de la Nueva España, siglo XVII", Relaciones, 15/59, 1994, pp. 45-64.

VAlVerde Abril, Juan J., "Traduttore traditore: Las tergiversaciones de Juan Ginés de Sepúlveda en su traducción de la Política de Aristóteles", en María Teresa Muñoz García de Iturrospe y Leticia Carrasco Reija (eds.), Miscellanea Latina, Madrid, Sociedad de Estudios Latinos-Universidad Complutense de Madrid, 2015, pp. 209-215.

VAn GuILK, Egbertus, Erasmus and his books, Toronto, University of Toronto Press, 2018.

Vollet, Matthias, "Sepúlveda: traductor y comentarista de Aristóteles: Política I", Ideas y valores, 119, 2002, pp. 137-143.

WIEACKER, Franz, Historia del derecho privado en la Edad Moderna, Madrid, Aguilar, 1957.

\section{Manuscritos}

AGI, México, 1089, L. 4, F.300V-301R, "Real cédula a la Audiencia de México para que incaute todos los ejemplares que hubiera en esas tierras de un libro que el doctor [Juan Ginés de] Sepúlveda ha publicado sobre las Indias sin licencia, y los envíe al Consejo de Indias”, Unidad Documental Simple, Madrid, 19 de octubre de 1550 .

Genaro Valencia Constantino es licenciado en Letras Cristianas y Clásicas por la Pontificia Universidad Salesiana (Roma, Italia), maestro en Letras Clásicas por la Universidad Nacional Autónoma de México. Actualmente cursa la maestría en Filosofía Antigua en la Universidad Panamericana, donde desarrolla una tesis sobre la filosofía de Séneca y su relación con la política y la retórica. Es miembro de la Asociación Mexicana de Estudios Clásicos desde 2010 y de la Asociación Latinoamericana de Filosofía Antigua desde 2019. Ha participado en congresos nacionales e internacionales. Sus temáticas de interés son la gramática latina (sintaxis y fraseología), literatura latina (Cicerón, Séneca), textos jurídicos romanos y la recepción de autores clásicos en los periodos moderno y novohispano. 